\title{
BALANCE DE GASES DE EFECTO INVERNADERO EN LECHERÍAS ESPECIALIZADAS DE COSTA RICA
}

\author{
William Sánchez-Ledezma
}

\section{RESUMEN}

Balance de gases de efecto invernadero en lecherías especializadas de Costa Rica. El objetivo de este estudio fue realizar el balance de Gases de Efecto Invernadero (GEI) en sistemas de lechería especializados representativos de la zona alta de la Región Central de Costa Rica, provincia de Cartago, ubicados en sitios agroecológicamente diferentes, entre 1800 y 2700 m de altitud, en las coordenadas 994'12" y 989'96" latitud norte y $83^{\circ} 85^{\prime} 15^{\prime \prime}$ y $83^{\circ} 87^{\prime} 80^{\prime \prime}$ longitud oeste, en pisos altitudinales de montano a montano bajo y zonas de vida de bosque húmedo a muy húmedo. La investigación se realizó durante un periodo de un año consecutivo (2014), utilizando la metodología propuesta por el Intergovernmental Panel on Climate Change (IPCC) en el 2006. Se cuantificó la fijación de carbono en el suelo, en los árboles de las cercas vivas y dispersos en potreros y bosque y las emisiones de metano $\left(\mathrm{CH}_{4}\right)$, óxido nitroso $\mathrm{N}_{2} \mathrm{O}$ y dióxido de carbono $\left(\mathrm{CO}_{2}\right)$ generadas por los rumiantes, el estiércol, los fertilizantes nitrogenados, los combustibles fósiles y la electricidad. Se utilizó el dióxido de carbono equivalente $\left(\mathrm{CO}_{2} \mathrm{eq}\right)$ como unidad de medida, determinando el balance de GEI mediante la diferencia entre la cantidad $\mathrm{CO}_{2}$ eq fijado y el emitido por el sistema. Se evidenció que los sistemas de lechería especializados evaluados, presentan un balance negativo de GEl, debido a que no fue posible cuantificar la fijación de carbono fijado en el suelo durante el corto periodo de evaluación (un año). Sin embargo, se demostró que el componente leñoso, conformado por el área de bosque, los árboles dispersos, las pasturas y las cercas vivas, retiene más del 50 \% del carbono emitido por los mismos sistemas. Además, se concluyó que las emisiones de carbono se podrían reducir, con una adecuada estructuración del hato, desechando los animales improductivos y optimizando la fertilización nitrogenada.

Palabras clave: metano, dióxido de carbono, óxido nitroso, carbono equivalente. 


\section{INTRODUCCIÓN}

Los Gases de Efecto Invernadero (GEI) se producen mediante procesos o mecanismos naturales, que han permitido a través del tiempo mantener una temperatura cálida en el planeta (González y Rodríguez, 1999). Sin embargo, después de la revolución industrial se han evidenciado aumentos en la concentración de los GEl en la atmósfera, situación que se asocia a efectos negativos en el ambiente, como el aumento en la temperatura de la tierra y del océano, el descongelamiento de los glaciares, el aumento en el nivel del mar e incidencia de fenómenos naturales extremos como sequías y exceso de lluvia (Friedrinch-Wilhelm y Werner, 2008; Shallcross et al., 2007).

El dióxido de carbono $\left(\mathrm{CO}_{2}\right)$ el metano $\left(\mathrm{CH}_{4}\right)$ y el óxido nitroso $\left(\mathrm{N}_{2} \mathrm{O}\right)$ son los gases más relevantes que conforman los GEl, los cuales tienen un potencial de calentamiento de 1,21 y 310, respectivamente (IPCC, 2006). A pesar de que el metano posee un mayor poder de calentamiento que el $\mathrm{CO}_{2}$, su tiempo de vida media en la atmósfera es de diez años (Moss, 2000; Niggli et al., 2009). Dentro del sector agropecuario, el $\mathrm{CO}_{2}$ se genera en su mayoría por la combustión de combustibles fósiles (gasolina y diesel) utilizados en el equipo agrícola, por su parte, el $\mathrm{CH}_{4}$ se genera por la fermentación que ocurre en el tracto digestivo de los animales, y el $\mathrm{N}_{2} \mathrm{O}$ por el uso de fertilizantes nitrogenados en las actividades agrícolas (Cabrera et al., 2010).

Mediante la Convención Marco de las Naciones Unidas sobre el Cambio Climático (CMNUCC), varios países han unido esfuerzos en busca de mitigar las emisiones de GEl de origen antropogénico. Un ejemplo es el tratado de Kioto celebrado en 1997, donde 196 países se comprometieron a realizar el inventario nacional de GEl y a reducir las emisiones en un 5\% con respecto a las emisiones de 1990 (Lascano y Cárdenas, 2010). Costa Rica, como país firmante de la convención, ha realizado tres inventarios nacionales utilizando la metodología propuesta por el Panel Intergubernamental de Expertos en Cambio Climático (por su siglas en inglés, IPCC), el cual ha definido las siguientes cuatro categorías como fuentes de emisión de GEl: a) energía; b) procesos industriales y uso de productos; c) agricultura, silvicultura y otros usos de la tierra (AFOLU) y d) desechos. En el último inventario llevado a cabo en Costa Rica en el año 2010, se encontró que la emisión de GEl a la atmósfera fue de 8788,84 $\mathrm{Gg}$ de $\mathrm{CO}_{2}$ equivalente, siendo los sectores de energía (combustibles y gases), industria y desechos los responsables del 80,6, 9,1 y 15,7\% de las emisiones, respectivamente, mientras que el sector AFOLU aportó un valor negativo (-473,29 Gg) debido a las grandes fijaciones de carbono que mantiene (IMN, 2014). Dentro del total de metano emitido por el AFOLU, la ganadería es responsable del $84 \%$ sin embargo, mediante el componente leñoso el sector fija el $48 \%$ del $\mathrm{CO}_{2}$ emitido por los otros sectores (IMN 2014).

Algunos investigadores coinciden que en Costa Rica los sistemas de producción bovina y de rumiantes en general, son los que tienen el mayor potencial de reducir las emisiones de GEl (Abarca, 2013; Botero, 2013), habiéndose encontrando una gran mayoría de las fincas ganaderas en balance positivo, es decir, fijando más GEl de los que emiten.

Actualmente, la ganadería bovina de Costa Rica tiene el reto de incrementar la productividad al menor costo posible y con la menor emisión de GEl. En los sistemas ganaderos del trópico húmedo, los animales interactúan con una gran cantidad de biomasa proporcionada por los árboles, arbustos, pastos y forrajes que existen en el ecosistema, que además de suministrar beneficios nutritivos a los animales son capaces de retener gran cantidad de dióxido de carbono, siendo en algunos casos mayor que la cantidad emitida por el mismo sistema de producción. Ante esta situación, se hace necesario cuantificar la retención y emisiones de $\mathrm{CO}_{2}$ equivalente en los sistemas de lechería especializada, con la finalidad de determinar su balance $y$, en caso de que éste sea negativo (mayores emisiones que capturas), buscar alternativas tecnológicas y de manejo que permitan reducir e incrementar la emisión y fijación de carbono, respectivamente.

El objetivo del estudio fue realizar el balance de gases con efecto invernadero (GEl) en tres sistemas de lechería especializados, representativos de la zona alta de la Región Central de Costa Rica, mediante la cuantificación del $\mathrm{CO}_{2}$ eq que fijan y emiten los principales componentes que interactúan en los sistemas. 


\section{MATERIALES Y MÉTODOS}

El estudio se realizó en tres fincas comerciales representativas de la Región Central de Costa Rica, ubicada en la Cordillera Volcánica Central del país, específicamente en las localidades de Cot, Santa Rosa y San Juan de Chicuá, de los cantones de Oreamuno y Central, provincia de Cartago.

Las fincas seleccionadas se ubican en sitios agroecológicamente diferentes, entre 1800 y $2700 \mathrm{~m}$ de altitud, entre las coordenadas 9॰94'12" y $9^{\circ} 89^{\prime} 96$ " latitud norte y $83^{\circ} 85^{\prime} 15^{\prime \prime}$ y $83^{\circ} 87^{\prime} 80^{\prime \prime}$ longitud oeste, en pisos altitudinales de montano a montano bajo, con zonas de vida de bosque húmedo a muy húmedo (Bolaños y Watson, 1993). Los suelos son profundos de origen volcánico del orden de los Andisoles.

En las tres fincas, predomina el pasto kikuyo (Kikuyuochloa clandestina) como especie principal que es consumido en pastoreo rotacional, con aprovechamientos de medio día a intervalos de 30 días de descanso. Las praderas seleccionadas para el estudio se establecieron hace aproximadamente 20 años y reciben una fertilización a base de 250, 50 y $50 \mathrm{~kg} \mathrm{ha}^{-1}$ de $\mathrm{N}, \mathrm{P}_{2} \mathrm{O}_{5}$ y $\mathrm{K}_{2} \mathrm{O}$, respectivamente. La dosis anual de $\mathrm{N}$ se administró durante la estación lluviosa, distribuida en fracciones iguales después de cada rotación, mientras que la dosis de fósforo y de potasio se distribuyó en partes iguales entre el inicio de la estación lluviosa (junio) y la estación seca, cuatro meses después (octubre).

Para realizar el balance de GEI, se cuantificó la cantidad de dióxido de carbono equivalente $\left(\mathrm{CO}_{2}\right.$ eq) emitido y fijado (t/año) por finca, por hectárea, por vaca lactante y por kilogramo de leche producido, esto mediante las ecuaciones propuestas por la directriz del IPCC (2006). Se utilizó el dióxido de carbono equivalente $\left(\mathrm{CO}_{2}\right.$ eq) como unidad de medida, con el fin de emplear la misma disposición de medida para las fijaciones y emisiones por los sistemas.

En cuanto a la emisión de los GEl, se cuantificó la producción de $\mathrm{CH}_{4}, \mathrm{~N}_{2} \mathrm{O}$ y $\mathrm{CO}_{2}$ producidos por la fermentación en el tracto digestivo de los rumiantes, manejo del estiércol, la fertilización nitrogenada de las pasturas y el uso de los combustibles fósiles y de electricidad. Se utilizó la metodología propuesta por el IPCC (2006), niveles 1 y 2, según la directriz del capítulo 10 (Emisiones del ganado y manejo de desechos sólidos y líquidos). El nivel 1 es el método más simple, donde se aplican los factores de emisión al grupo de animales, mientras que en el nivel 2 se considera el peso de los animales, la etapa fisiológica, el manejo, la alimentación, el nivel de producción y otros factores relacionados con la emisión. Para estimar la fijación de $\mathrm{CO}_{2}$ eq se consideraron los siguientes cuatro componentes: el suelo, las cercas vivas, los árboles y arbustos dispersos en las pasturas y el bosque secundario (con escasa perturbación antropológica), considerando la metodología propuesta por Veldkamp (1993), el IPCC (2006), De Melo y Abarca (2008) y Russo (2009). En la Figura 1 se presenta el diagrama del procedimiento y la metodología utilizados para estimar el balance de los GEl.

El estudio se limitó al área física y geográfica donde se ubica cada sistema de producción y durante un periodo de un año productivo. Se incluyeron únicamente las actividades e insumos sobre los cuales se puede intervenir en caso de que sea necesario reducir la emisión de los GEl o incrementar la fijación de carbono durante el proceso productivo. 


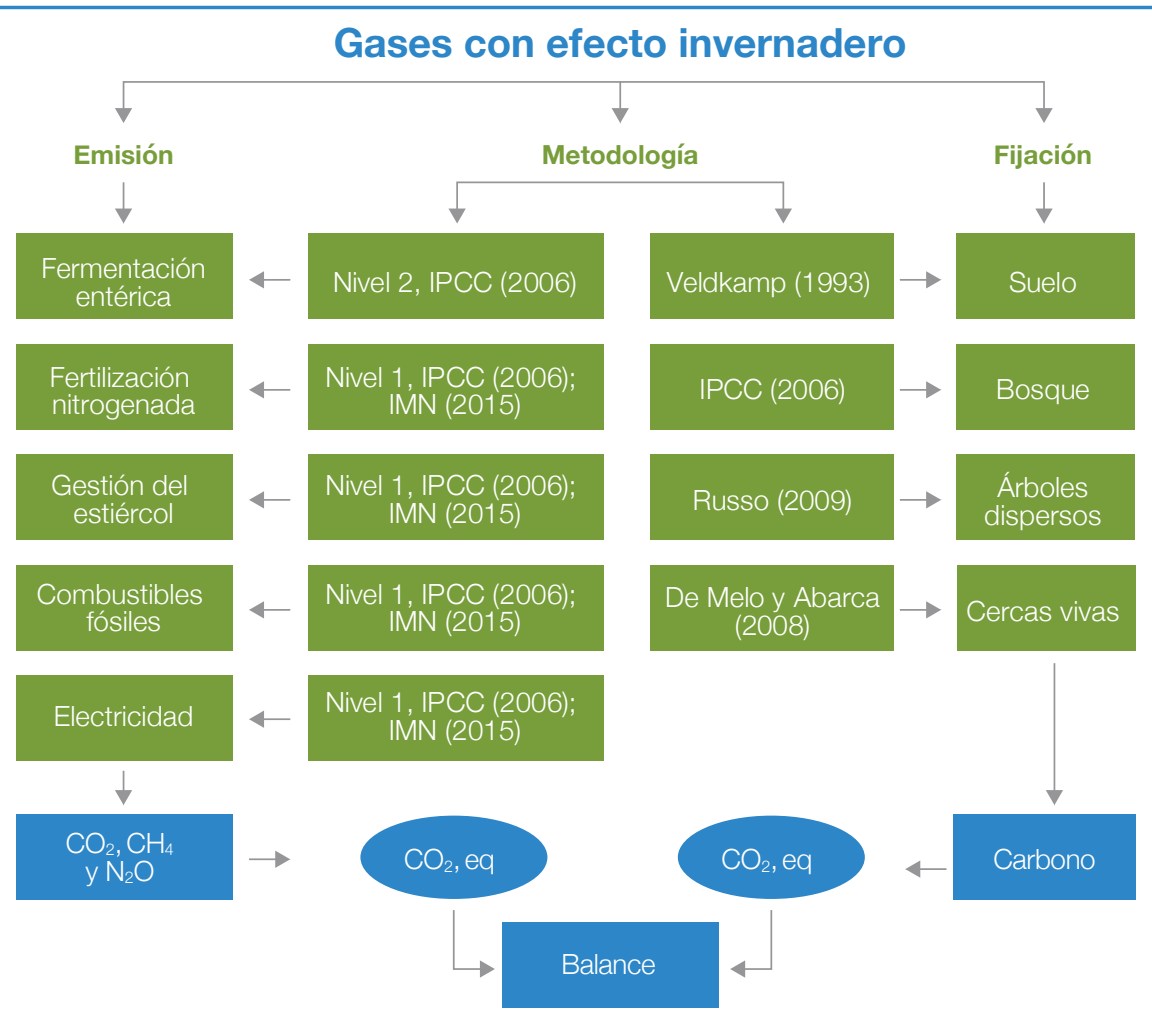

Fuente: $\quad$ Adaptado de García (2014).

Figura 1. Procedimiento y metodología utilizados para estimar el balance de los GEl en tres explotaciones de lechería especializada en la zona alta de Cartago, Costa Rica. 2014.

\section{Estimación de la emisión de los GEI}

Como se mencionó anteriormente, para estimar las emisiones de los GEl se cuantificó la producción de $\mathrm{CH}_{4}, \mathrm{~N}_{2} \mathrm{O}$ y $\mathrm{CO}_{2}$ emitidos por la fermentación en el tracto digestivo de los rumiantes, la gestión del estiércol, la fertilización nitrogenada de las pasturas y el uso de combustible fósiles y de electricidad.

Fermentación en el tracto digestivo de los animales: Para estimar las emisiones de metano, se utilizó la metodología propuesta por el IPCC (2006) basada en la directriz del nivel 2 del capítulo 10. El hato se agrupó en cuatro categorías (vacas en producción y secas, novillas y terneras). Se tomó en cuenta el peso vivo medio y la ganancia de peso diaria por categoría y, en el caso de las vacas lactantes, la producción y el contenido de grasa en la leche. También se consideró el consumo de alimento balanceado por categoría, así como la energía digestible de este alimento y la digestibilidad de la materia seca (DIVMS) y el contenido en Fibra Neutro Detergente (FND) de la pastura. Los cálculos se realizaron mediante la siguiente ecuación:

$$
\mathrm{Fe}=[(\mathrm{EB} \times \mathrm{Ym} \times 365 \text { días }) \div(55,65 \mathrm{MJ} / \mathrm{kg} \mathrm{CH} 4)]
$$

Donde:

$\mathrm{Fe}=$ = Factor de emisión ( $\mathrm{kg} \mathrm{CH} \mathrm{CH}_{4}$ animal/año).

EB = Energía bruta (MJ animal/día).

Ym = Tasa de conversión de EB en metano (pasto: 6,5\% y concentrado: 3,0\%) según IPCC (2006).

Finalmente, la cantidad de $\mathrm{CH}_{4}$ obtenida se multiplicó por el potencial de calentamiento global del metano (21) para determinar la cantidad de dióxido de carbono equivalente $\left(\mathrm{CO}_{2} \mathrm{eq}\right)$.

Gestión del estiércol: Con respecto a las excretas que los animales depositan directamente en la pastura, se utilizó la directriz del IPCC (2006) nivel 1, que indica que en estos casos se debe considerar una emisión de un $\mathrm{kg}$ de $\mathrm{CH}_{4}$ animal/ año, debido a que en el trópico húmedo no existe información relacionada sobre la dinámica de las excretas depositadas por los rumiantes en los pastizales. 
Para cuantificar las emisiones de $\mathrm{CH}_{4}$ y de $\mathrm{N}_{2} \mathrm{O}$ producto del acúmulo de estiércol o elaboración de compost, se utilizó la metodología propuesta por IPCC (2006) nivel 1 y los factores de emisión propuestos por el IMN (2015). El $\mathrm{CO}_{2}$ no se toma en cuenta por estar en un ciclo biogeoquímico. Los cálculos se realizaron mediante la siguiente ecuación:

\section{$\mathrm{CH}_{4} \circ \mathrm{N}_{2} \mathrm{O}-\mathrm{N}=\mathrm{ESa} \times \mathrm{Fe}$}

Donde:

$\mathrm{CH}_{4} \quad=$ Emisión de $\mathrm{CH}_{4}$ (kg/año).

$\mathrm{N}_{2} \mathrm{O}-\mathrm{N}=$ Emisión de $\mathrm{N}_{2} \mathrm{O}$ ( $\mathrm{kg} /$ año).

ESa = Cantidad de estiércol sólido acumulado (kg/año).

$\mathrm{Fe} \quad=$ Factor de emisión de $\mathrm{CH}_{4}(4 \mathrm{~g})$ y de $\mathrm{N}_{2} \mathrm{O}(0,3 \mathrm{~g}) \mathrm{kg} / \mathrm{ESa}(\mathrm{INM}, 2015)$.

El acúmulo de aguas residuales por varios dias, producto de la limpieza de las instalaciones de la lechería, también producen metano, óxido nitroso y dióxido de carbono; sin embargo, en las fincas estudiadas no existen acúmulos de estos residuos, por lo que no fueron consideradas en el balance.

La cantidad de $\mathrm{CO}_{2}$ eq se obtuvo multiplicando el valor obtenido de metano y óxido nitroso por el potencial de calentamiento global de cada gas (21 y 310, respectivamente), de acuerdo con la propuesta del IPCC (2006).

Fertilización nitrogenada: La fertilización nitrogenada de los pastos y los forrajes también emiten óxido nitroso $\left(\mathrm{N}_{2} \mathrm{O}\right)$, por lo que fue necesario cuantificar la cantidad de nitrógeno aplicado en cada finca durante el año. Posteriormente, se calculó la emisión de $\mathrm{N}_{2} \mathrm{O}$ con base en la metodología propuesta por el IPCC (2006) nivel 1, utilizando la siguiente fórmula:

$$
\mathrm{N}_{2} \mathrm{O}-\mathrm{N}=[(\mathrm{NFa} \times \mathrm{Af} \times 0,01) \times(44 / 14)]
$$

Donde:

$\begin{array}{ll}\mathrm{N}_{2} \mathrm{O}-\mathrm{N} & =\text { Emisión de óxido nitroso (kg/año). } \\ \mathrm{NFa} & =\text { Cantidad de nitrógeno químico } \\ & \text { aplicado al suelo (kg/año). } \\ \mathrm{Af} & =\text { Área fertilizada (ha). } \\ 0,01 & =\text { Factor de emisión }\left(\mathrm{kg} \mathrm{N} \mathrm{N}_{2} \mathrm{O}-\mathrm{N} \text { por kg N). }\right. \\ 44 & =\text { Peso molecular del } \mathrm{NO}_{2} . \\ 14 & =\text { Peso atómico del nitrógeno. }\end{array}$

Posteriormente, la cantidad de $\mathrm{CO}_{2}$ eq se obtuvo multiplicando el valor obtenido en la ecuación por el potencial de calentamiento global (310) del óxido nitroso (IPCC, 2006).

Combustibles fósiles: El uso de combustibles fósiles en los sistemas ganaderos provoca la emisión de $\mathrm{CH}_{4}, \mathrm{~N}_{2} \mathrm{O}$ y $\mathrm{CO}_{2}$ al ambiente. Para determinar las emisiones de dichos gases se utilizó la metodología propuesta por el IPCC (2006) nivel 1, utilizando los factores de conversión propuestos por el IMN (2015), según las características de nuestros combustibles. Los cálculos se realizaron utilizando la siguiente formula:

$$
\begin{gathered}
\mathrm{CO}_{2} \mathrm{eq}=\sum\left(\mathrm{CC} \times \mathrm{EF} \mathrm{CO}_{2}\right)+ \\
{\left[\sum\left(\mathrm{CC} \times \mathrm{EF} \mathrm{CH}_{4}\right) \times 21\right]+\left[\sum\left(\mathrm{CC} \times \mathrm{EF} \mathrm{N}_{2} \mathrm{O}\right) \times 310\right]}
\end{gathered}
$$

Donde:

$\mathrm{CO}_{2}$ eq = Emisión de $\mathrm{CO}_{2}$ equivalente por combustibles fósiles (t/año).

CC = Consumo de combustible (litros).

EF $\quad=$ Factor de emisión para el $\mathrm{CO}_{2}, \mathrm{CH}_{4}$ y $\mathrm{N}_{2} \mathrm{O}$ según características del combustible costarricense $\left(\mathrm{CO}_{2}=\right.$ gasolina 2,26 y diesel 2,69 kg/litro; $\mathrm{CH}_{4}=$ gasolina 0,3265 y diesel 0,363 g/litro; y $\mathrm{N}_{2} \mathrm{O}=$ gasolina 0,01959 y diesel 0,2178 g/litro (IMN, 2015).

21 y $310=$ Potencial de calentamiento global del $\mathrm{CH}_{4}$ y $\mathrm{N}_{2} \mathrm{O}$, respectivamente.

Electricidad: Debido a que en Costa Rica, parte de la electricidad se produce mediante la utilización de energía proveniente de combustibles fósiles (diesel) y éstos emiten $\mathrm{CO}_{2}$, por lo que es necesario cuantificar el gasto de electricidad en Kwh/año, para finalmente determinar la emisión de $\mathrm{CO}_{2}$ eq mediante la metodología propuesta por el IPCC (2006) nivel 1. En este caso, se utilizaron los factores de conversión propuestos por el IMN (2015), según las características del combustible de Costa Rica. Los cálculos se realizaron mediante la siguiente ecuación:

$$
\mathrm{CO}_{2} \mathrm{eq}=\mathrm{Kwh} \times \mathrm{Fe}
$$

Donde:

$\mathrm{CO}_{2}$ eq = Dióxido de carbono equivalente.

Kwh = Consumo de electricidad (Kwh/año).

Fe $\quad=$ Factor de emisión $(0,1170 \mathrm{~kg}$ $\mathrm{CO}_{2}$ eq Kwh; INM, 2015). 


\section{Estimación de la fijación de carbono}

Para cuantificar la fijación de $\mathrm{CO}_{2}$ eq para cada explotación lechera, se consideraron los siguientes cuatro componentes: suelo, bosque secundario, árboles y arbustos dispersos en las pasturas y las cercas vivas.

Fijación de $\mathrm{CO}_{2}$ eq en el suelo: El carbono orgánico total (COT) retenido en el suelo durante un ciclo anual, se determinó mediante la metodología propuesta por el IPCC (2006), incluyendo la densidad aparente del suelo (Veldkamp, 1993). Al inicio y final del año se tomaron tres muestras de $250 \mathrm{~g}$ de suelo por finca, a $10 \mathrm{~cm}$ de profundidad, para analizar la concentración de materia orgánica $(\mathrm{MO})$, el contenido de carbono y la densidad aparente (Forsythe 1972). El cálculo del COT en el suelo al inicio y al final del año se realizó mediante la siguiente fórmula:

$$
\mathrm{COT}=\% \mathrm{Cs} \times \mathrm{Ls} \times \mathrm{Da} \times 10^{4}
$$

Donde:

$$
\begin{array}{ll}
\text { COT } & =\text { Carbono Orgánico Total }(\mathrm{t} / \mathrm{ha}) . \\
\text { Cs } & =\text { Contenido de carbono en el suelo }(\mathrm{g} / \mathrm{g}) . \\
\text { Ls } & =\text { Lámina de suelo }(\mathrm{cm}) . \\
\text { Da } & \text { = Densidad aparente del suelo. }
\end{array}
$$

Posteriormente, se calculó el dióxido de carbono equivalente $\left(\mathrm{CO}_{2}\right.$ eq) en cada finca multiplicando el carbono orgánico total obtenido en el suelo por la relación entre el peso molecular del $\mathrm{CO}_{2}$ y del carbono (44/12), como se presenta en la siguiente fórmula:

$$
\mathrm{CO}_{2} \mathrm{eq}=\mathrm{COT} \times(44 / 12)
$$

Donde:

$$
\begin{array}{ll}
\mathrm{CO}_{2} \text { eq } & =\text { Dióxido de carbono equivalente } \\
& \text { retenido en el suelo }(\mathrm{t} / \mathrm{ha}) . \\
\mathrm{COT} & =\text { Carbono orgánico total }(\mathrm{t} / \mathrm{ha}) \\
44 & =\text { Peso molecular del } \mathrm{CO}_{2} . \\
12 & =\text { Peso atómico del carbono. }
\end{array}
$$

Finalmente, por diferencia entre el $\mathrm{CO}_{2}$ eq existe al final e inicio de año, se determinó el carbono orgánico total retenido durante el ciclo anual.
Fijación de $\mathrm{CO}_{2}$ eq en el bosque: La estimación del $\mathrm{CO}_{2}$ eq fijado por el bosque existente en cada finca, se calculó utilizando la metodología propuesta por el IPCC (2006), mediante la siguiente fórmula:

$$
\mathrm{CO}_{2} \mathrm{eq}=\mathrm{A} \times \mathrm{Tc} \times 0,47
$$

Donde:

$\mathrm{CO}_{2}$ eq = dióxido de carbono equivalente (Mg).

A $\quad=$ Área de bosque secundario (ha).

Tc $=$ Tasa de crecimiento $(7,0)$ (IPCC, 2006).

$0,47=$ Concentración de carbono en la biomasa (IPCC, 2006).

Fijación de $\mathrm{CO}_{2}$ eq en los árboles y arbustos dispersos en las pasturas: La estimación del $\mathrm{CO}_{2}$ eq fijado por los árboles y arbustos dispersos en las pasturas, se realizó mediante la metodología propuesta por Russo (2009). En el área de pastos se seleccionaron tres sectores de dos hectáreas cada uno, representativos en cuanto a densidad de árboles, altura y Diámetro a la Altura del Pecho (DAP). En cada sector se contó el número de árboles, seleccionando cinco para medir la altura del fuste y el DAP. Los cinco árboles fueron seleccionados en una escala de 1 a 5 , donde uno representa el árbol de menor altura y DAP y cinco el más alto y de mayor diámetro. La altura de los árboles se midió utilizando un clinómetro, multiplicando la distancia entre el árbol y el clinómetro (12 metros) por el ángulo que registró el clinómetro. Al resultado de esta operación se le sumó la altura entre el nivel del suelo y la posición del clinómetro cuando se realizó la medición del ángulo (altura al ojo).

En cada sector también se contó el número de arbustos, seleccionado cinco para medir la altura y el diámetro. La altura del tronco se midió desde el suelo hasta la primera difusión importante, y el diámetro a $40 \mathrm{~cm}$ de altura.

Posteriormente, se estimó el volumen del tronco de los árboles y de los arbustos muestreados utilizando la siguiente formula:

$$
\mathrm{Vt}=\pi \times r^{2} \times a
$$

Donde:

$\mathrm{V}_{\mathrm{t}} \quad=$ Volumen del tronco $\left(\mathrm{m}^{3}\right)$.

$\pi \quad=$ Constante.

r = Radio.

a $=$ Altura del tallo. 
Seguidamente, se determinó el peso del tronco de cada árbol o arbusto muestreado utilizando la siguiente fórmula:

$$
\mathrm{Pt}=\mathrm{Vt} \times \mathrm{Dm} \times \mathrm{Fe}
$$

Donde:

Pt $\quad=$ Peso del tronco $(\mathrm{kg})$.

Vt $\quad=$ Volumen del tronco $\left(\mathrm{m}^{3}\right)$.

$\mathrm{Dm} \quad=$ Densidad de la madera (0,50) (IPCC 2006).

$\mathrm{Fe} \quad=$ Factor de expansión (ramas y raíces) de la madera (0,30\%; Russo, 2009).

Además se determinó el peso de carbono en el tronco mediante la siguiente fórmula:

$$
\mathrm{PCt}=\mathrm{Pt} \times 0,47
$$

Donde:

PCt $=$ Peso del carbono en el tronco.

Pt $=$ Peso del tronco.

0,47 = Concentración de carbono en la biomasa (IPCC, 2006).

Finalmente, se determinó el $\mathrm{CO}_{2}$ eq retenido en los árboles y en los arbustos mediante la siguiente fórmula:

$$
\mathrm{CO}_{2} \mathrm{eq}=\mathrm{PCt} \times(44 / 12)
$$

Donde:

PCt $\quad=$ Peso del carbono en el tronco del árbol o arbusto.

$44=$ Peso molecular del $\mathrm{CO}_{2}$.

$12=$ Peso atómico del carbono.

Por último, se obtuvo la cantidad total de $\mathrm{CO}_{2}$ eq fijada por los árboles y arbustos existentes en cada finca multiplicando el $\mathrm{CO}_{2}$ eq obtenido por árbol o arbusto por la cantidad existente de cada uno.

Fijación de $\mathrm{CO}_{2}$ eq en las cercas vivas: Para estimar el $\mathrm{CO}_{2}$ eq almacenado en las cercas vivas, se utilizó la metodología propuesta por De Melo y Abarca (2008), la cual consiste en realizar las siguientes mediciones:

- Total de metros lineales de cerca viva existentes en la finca.

- Cantidad de árboles promedio por metro lineal.

- Altura del fuste del árbol o tronco.
- Diámetro del árbol a la altura de pecho (DAP).

- Densidad estimada de la madera $(0,50)$ (IPCC 2006).

- Concentración de carbono en la biomasa (0,47\%) (IPCC 2006).

- Factor de expansión de la madera $(0,30 \%)$ (Russo 2009).

La cuantificación del total de metros lineales de cerca viva, se realizó mediante el recorrido de los linderos de todas las cercas vivas existentes en cada finca, con el apoyo del GPS. Posteriormente, se seleccionaron tres sectores de 50 metros lineales cada uno, representativos del total, pero diferentes entre sí en cuanto a densidad de árboles, altura y DAP de los mismos. Se consideraron tres categorías: baja, media y alta. En cada sector se seleccionaron diez árboles, a los cuales se les midió la altura del fuste o tronco (eje principal) y el DAP. El volumen del tronco de cada árbol (Vt), el peso del tronco (Pt) y el carbono retenido en éste (PCt), fueron calculados de acuerdo con las ecuaciones anteriormente descritas.

Finalmente, se estimó el dióxido de carbono equivalente $\left(\mathrm{CO}_{2} \mathrm{eq}\right)$ por metro lineal, y posteriormente por el total de la cerca viva, mediante las siguientes fórmulas:

${ }^{1} \mathrm{CO}_{2}$ eq $=\mathrm{PCt} \times(44 / 12)$ y ${ }^{2} \mathrm{CO}_{2} \mathrm{eq}={ }^{1} \mathrm{CO}_{2} \mathrm{eq} \times \mathrm{TCV}$

Donde:

${ }^{1} \mathrm{CO}_{2}$ eq $=$ Dióxido de carbono equivalente retenido por $\mathrm{m}$ de cerca viva $(\mathrm{kg} / \mathrm{m})$.

${ }^{2} \mathrm{CO}_{2}$ eq $=$ Dióxido de carbono equivalente retenido por el total de metros lineales de cerca viva (t).

PCt $\quad=$ Peso de carbono del tronco $(\mathrm{kg})$.

TCV = Total de metros lineales de cerca viva $(\mathrm{m})$.

$44=$ Peso molecular del $\mathrm{CO}_{2}$.

$12=$ Peso atómico del carbono.

Una vez estimado el $\mathrm{CO}_{2}$ eq emitido y retenido en cada finca, se realizó el correspondiente balance de $\mathrm{CO}_{2}$ eq, mediante la siguiente fórmula:

Balance $\mathrm{GEI}=\mathrm{CO}_{2}$ eq fijado $-\mathrm{CO}_{2}$ eq emitido. Donde:

GEI = Gas de Efecto Invernadero.

$\mathrm{CO}_{2}$ eq $=$ Dióxido de carbono equivalente. 


\section{Análisis de laboratorio}

Se analizó el contenido de Materia Seca (MS), Materia Orgánica (MO), Carbono (C) y Densidad Aparente (DA) del suelo. El contenido en MS se obtuvo por pérdida de peso tras la desecación de $250 \pm 0,01 \mathrm{~g}$ de suelo húmedo en estufa a 105
${ }^{\circ} \mathrm{C}$ por 48 horas (AOAC, 1970), la MO mediante el método de Walkey y Black (1934), el contenido de carbono a través del método de combustión directo de LECO (Tabatabai y Bremner, 1970) y la densidad aparente mediante la metodología propuesta por Forsythe (1972).

\section{RESULTADOS Y DISCUSIÓN}

Las fincas analizadas se dedican únicamente a la producción de leche de vaca, mediante un sistema de lechería especializado, en áreas que oscilan entre 17 y 44,8 hectáreas. En la Cuadro 1 se detalla la distribución del uso del suelo en cada sistema de producción.

Cuadro 1. Distribución del uso del suelo (hectáreas) en tres fincas de lechería especializadas en la zona alta de Cartago. Costa Rica. 2014.

\begin{tabular}{|l|c|c|c|}
\hline \multirow{2}{*}{ Cobertura vegetal } & \multicolumn{3}{|c|}{ Sistema de producción } \\
\cline { 2 - 4 } & Cot & $\begin{array}{r}\text { Santa } \\
\text { Rosa }\end{array}$ & $\begin{array}{r}\text { San Juan } \\
\text { de Chicuá }\end{array}$ \\
\hline Bosque & 0 & 17,0 & 3,0 \\
\hline Pastura principal & 14,0 & 24,8 & 27,0 \\
\hline Cultivos forrajeros & 3,0 & 3,0 & 7,0 \\
\hline Total & $\mathbf{1 7 , 0}$ & $\mathbf{4 4 , 8}$ & $\mathbf{3 7 , 0}$ \\
\hline
\end{tabular}

Como se observa en Cuadro 1, la finca ubicada en la localidad de Cot no dispone de área de bosque, mientras que en Santa Rosa y en San Juan de Chicuá destinan el 38 y el $8 \%$ de la superficie total a bosque, al que se restringe el ingreso de animales principalmente por la alta pendiente. También se observa, que la finca de Cot y San Juan de Chicuá destinan más área a cultivos forrajeros (18 y 19 \%, respectivamente), en comparación con Santa Rosa, que dedica únicamente el $7 \%$ a dicho recurso.

Con respecto a la población bovina, en el Cuadro 2 se detalla la estratificación del hato, en número de cabezas disponibles en cada finca.
Cuadro 2. Estratificación del hato bovino (número de cabezas) en tres fincas de lechería especializada en la zona alta Cartago. Costa Rica. 2014.

\begin{tabular}{|l|c|c|c|}
\hline \multirow{2}{*}{ Categoría de animal } & \multicolumn{3}{|c|}{ Sistema de producción } \\
\cline { 2 - 4 } & Cot & $\begin{array}{r}\text { Santa } \\
\text { Rosa }\end{array}$ & $\begin{array}{c}\text { San } \\
\text { Juan de } \\
\text { Chicuá }\end{array}$ \\
\hline Terneras menores 1 año & 18 & 50 & 35 \\
\hline Novillas de 1 a 2,5 años & 26 & 20 & 50 \\
\hline Vacas secas & 27 & 25 & 25 \\
\hline Vacas en producción & 62 & 95 & 105 \\
\hline \multicolumn{1}{|c|}{ Total } & 133 & 190 & 215 \\
\hline
\end{tabular}

El porcentaje de animales adultos con respecto al hato total es semejante entre fincas, con valores que oscilan entre el 61 y el $67 \%$. Sin embargo, el porcentaje de animales adultos en ordeño es mayor en Santa Rosa y en San Juan de Chicuá ( $80 \pm 1,1$ $\%)$ que en Cot (70 \%). Lo mismo sucede con la disponibilidad de animales de reemplazo en Santa Rosa y en San Juan de Chicuá (39 $\pm 1,9 \%)$, en comparación con la localidad de Cot (33\%).

En relación con los insumos que emiten GEl al ambiente, en las tres fincas se utilizan fertilizantes nitrogenados, combustibles fósiles (gasolina y diesel) y electricidad como fuente de energía para el funcionamiento de la maquinaria agrícola. La electricidad es considerada como insumo emisor de GEI, debido a que parte de la energía eléctrica de Costa Rica es producida mediante la utilización de hidrocarburos. En la Cuadro 3 se detalla la cantidad de fertilizante, combustible fósiles y electricidad utilizada en cada sistema de producción. 
Cuadro 3. Cantidad de nitrógeno, diesel, gasolina y electricidad utilizada en tres fincas de lechería especializada en la zona alta de Cartago. Costa Rica. 2014.

\begin{tabular}{|l|c|c|c|c|}
\hline \multirow{2}{*}{ Insumo } & \multirow{2}{*}{$\begin{array}{c}\text { Unidad de } \\
\text { medida }\end{array}$} & \multicolumn{3}{|c|}{ Sistema de Producción } \\
\cline { 3 - 5 } & Cot & $\begin{array}{c}\text { Santa } \\
\text { Rosa }\end{array}$ & $\begin{array}{c}\text { San } \\
\text { Juan de } \\
\text { Chicuá }\end{array}$ \\
\hline Nitrógeno & $\mathrm{kg} / \mathrm{ha} / \mathrm{año}$ & 400 & 450 & 415 \\
\hline Diesel & litros/año & 3.410 & 4.400 & 5.500 \\
\hline Gasolina & litros/año & 1.100 & 2.750 & 2.750 \\
\hline Electricidad & Kwh/año & 19.800 & 30.000 & 33.000 \\
\hline
\end{tabular}

En cuanto a la producción de leche, la finca ubicada en San Juan de Chicuá fue la que alcanzó la mayor producción total (958,1 t/año), debido a que es la que cuenta con mayor superficie y número de vacas dedicadas a la actividad. Sin embargo, la producción de leche por hectárea fue semejante en las tres fincas (28,3 \pm 38 t/ha/año). En el Cuadro 4 se detallan los rendimientos de leche registrados en cada finca.

Cuadro 4. Producción de leche por finca, vaca y hectárea en tres fincas de lechería especializada en la zona alta de Cartago.

\begin{tabular}{|c|c|c|c|c|c|}
\hline \multirow{3}{*}{$\begin{array}{l}\text { Sistema de } \\
\text { producción }\end{array}$} & \multirow{3}{*}{$\begin{array}{c}\text { Área } \\
\text { de } \\
\text { gana- } \\
\text { dería } \\
\text { (ha) }\end{array}$} & \multirow{3}{*}{$\begin{array}{l}\text { Vacas } \\
\text { en } \\
\text { produc- } \\
\text { ción }\end{array}$} & \multicolumn{3}{|c|}{ Producción de leche } \\
\hline & & & Vaca & finca & hectárea \\
\hline & & & $\begin{array}{l}\text { (kg/ } \\
\text { dia) }\end{array}$ & \multicolumn{2}{|c|}{ (t/año) } \\
\hline Cot & 17,0 & 62 & 21 & 475,2 & 28,0 \\
\hline Santa Rosa & 27,8 & 95 & 23 & 797,5 & 28,7 \\
\hline $\begin{array}{l}\text { San Juan } \\
\text { de Chicuá }\end{array}$ & 34,0 & 105 & 25 & 958,1 & 28,1 \\
\hline
\end{tabular}

\section{Emisión de gases de efecto invernadero}

En Cuadro 5 se presenta el detalle de las emisiones de dióxido de carbono $\left(\mathrm{CO}_{2}\right)$, metano $\left(\mathrm{CH}_{4}\right)$ y óxido nitroso $\left(\mathrm{N}_{2} \mathrm{O}\right)$ por componente en cada finca.

Cuadro 5. Emisión de dióxido de carbono $\left(\mathrm{CO}_{2}\right)$, metano $\left(\mathrm{CH}_{4}\right)$ y óxido nitroso $\left(\mathrm{N}_{2} \mathrm{O}\right)$ en t/año/por fuente de emisión, en tres fincas de lechería especializada en la zona alta de Cartago. Costa Rica. 2014.

\begin{tabular}{|c|c|c|c|c|c|c|c|c|c|}
\hline \multirow{3}{*}{ Fuente de emisión } & \multicolumn{9}{|c|}{ Sistema de producción } \\
\hline & \multicolumn{3}{|c|}{ Cot } & \multicolumn{3}{|c|}{ Santa Rosa } & \multicolumn{3}{|c|}{ San Juan de Chicuá } \\
\hline & $\mathrm{CO}_{2}$ & $\mathrm{CH}_{4}$ & $\mathbf{N}_{2} \mathrm{O}$ & $\mathrm{CO}_{2}$ & $\mathrm{CH}_{4}$ & $\mathrm{~N}_{2} \mathrm{O}$ & $\mathrm{CO}_{2}$ & $\mathrm{CH}_{4}$ & $\mathbf{N}_{2} \mathrm{O}$ \\
\hline Fermentación digestiva & 0 & 11,43 & 0 & 0 & 14,72 & 0 & 0 & 19,44 & 0 \\
\hline Fertilización nitrogenada & 0 & 0 & 0,081 & 0 & 0 & 0,162 & 0 & 0 & 0,162 \\
\hline Gestión del estiércol & 2,56 & 0,215 & 0,005 & 2,84 & 0,478 & 0,019 & 3,87 & 0,597 & 0,024 \\
\hline Combustible & 11,02 & 0,002 & 0,0001 & 12,28 & 0,002 & 0,0001 & 19,86 & 0,003 & 0,0002 \\
\hline Electricidad & 2,32 & 0 & 0 & 3,51 & 0 & 0 & 3,90 & 0 & 0 \\
\hline Total & 15,90 & 11,65 & 0,09 & 18,63 & 15,20 & 0,181 & 27,63 & 20,04 & 0,186 \\
\hline
\end{tabular}

En cuanto a las emisiones de $\mathrm{CO}_{2}$, el uso de combustibles fósiles fue la principal fuente emisora del gas (69,0 $\pm 2,99 \%)$, distribuyéndose el resto en partes semejantes entre la gestión del estiércol y el uso de la electricidad. En el caso del $\mathrm{CH}_{4}$, la principal emisión proviene de la fermentación en el tracto digestivo de los animales (97,3 \pm 0,69\%), aportando la gestión del estiércol y el uso de combustibles fósiles menos del 2,7 $\pm 0,71 \%)$. También se determinó que el $88,9 \pm 1,55$ y el 9,7 $\pm 3,76 \%$ de las emisiones de óxido nitroso, provienen de la fertilización nitrogenada y de gestión del estiércol, respectivamente, aportando el resto por el uso de combustibles fósiles.

De los tres principales $\mathrm{GEI}\left(\mathrm{CO}_{2}, \mathrm{CH}_{4}\right.$ y $\left.\mathrm{N}_{2} \mathrm{O}\right)$ el dióxido de carbono es el que más se produce en las tres fincas, superando en términos medios al 
metano y al óxido nitroso en 5,1 $\pm 2,20$ y 20,6 \pm 6,10 t/año, respectivamente. Sin embargo, al multiplicar las cantidades emitidas de cada gas por su respectivo potencial de calentamiento $\left(\mathrm{CO}_{2}=1, \mathrm{CH}_{4}=21\right.$ y $\mathrm{N}_{2} \mathrm{O}=310$ ), las emisiones de metano expresadas en $\mathrm{CO}_{2}$ eq, superan en 16 y 7 veces a las de dióxido de carbono y óxido nitroso, respectivamente. En el Cuadro 6 se presenta el detalle de la emisión de $\mathrm{CH}_{4}$ por finca, hectárea y kilogramo de leche producido, procedente de la fermentación en el tracto digestivo de los animales y de la gestión del estiércol, que son los dos principales contribuyentes.

Cuadro 6. Emisión de metano por finca, por hectárea y kilogramos de leche producidos, en tres fincas de lechería especializada en la zona alta de Cartago. Costa Rica. 2014.

\begin{tabular}{|c|c|c|c|}
\hline \multirow{2}{*}{ Emisión de metano } & \multicolumn{2}{|c|}{ toneladas $\mathbf{C H}_{4} / \mathbf{a n ̃ o}$} & \multirow{2}{*}{$\begin{array}{c}\mathrm{CH} 4(\mathrm{~g}) / \\
\mathrm{kg} \\
\text { leche }\end{array}$} \\
\hline & Por finca & $\begin{array}{c}\text { Por } \\
\text { hectárea }\end{array}$ & \\
\hline \multicolumn{4}{|c|}{ Fermentación entérica } \\
\hline Cot & 11,43 & 0,672 & 24,05 \\
\hline Santa Rosa & 14,72 & 0,529 & 18,46 \\
\hline San Juan de Chicuá & 19,44 & 0,572 & 20,29 \\
\hline \multicolumn{4}{|c|}{ Gestión del estiércol } \\
\hline Cot & 0,215 & 0,013 & 0,45 \\
\hline Santa Rosa & 0,478 & 0,017 & 0,60 \\
\hline San Juan de Chicuá & 0,597 & 0,018 & 0,62 \\
\hline \multicolumn{4}{|c|}{ Total } \\
\hline Cot & 11,65 & 0,685 & 24,51 \\
\hline Santa Rosa & 15,20 & 0,546 & 19,06 \\
\hline San Juan de Chicuá & 20,04 & 0,590 & 20,91 \\
\hline Promedio & 15,63 & 0,607 & 21,49 \\
\hline
\end{tabular}

La finca de Cot produjo la menor cantidad de metano (11,65 t/año), aunque es el sitio donde se emite más $\mathrm{CH}_{4}$ por hectárea $(0,685$ t/año) y por kilogramo de leche producido $(24,51 \mathrm{~g})$. Las fincas de Santa Rosa y San Juan de Chicuá emitieron, en promedio, un $17,1 \pm 4,54$ y un $18,5 \pm 5,34 \%$ menos de metano por hectárea y kilogramo de leche, respectivamente, que en Cot. Por su parte, en la finca de Santa Rosa se produjeron menores emisiones de metano (15,20 t/año) que en la de San Juan de Chicuá (20,04 t/año); sin embargo, las emisiones por hectárea $(0,568 \pm 0,0311$ t/año) y kilogramo de leche producido $(20 \pm 1,31 \mathrm{~g})$ fueron semejantes.
Como era de esperar, las vacas en producción emitieron mayor cantidad de metano procedente de la fermentación en el tracto digestivo que las vacas secas y los animales de menor tamaño, como se detalla en la Figura 2.

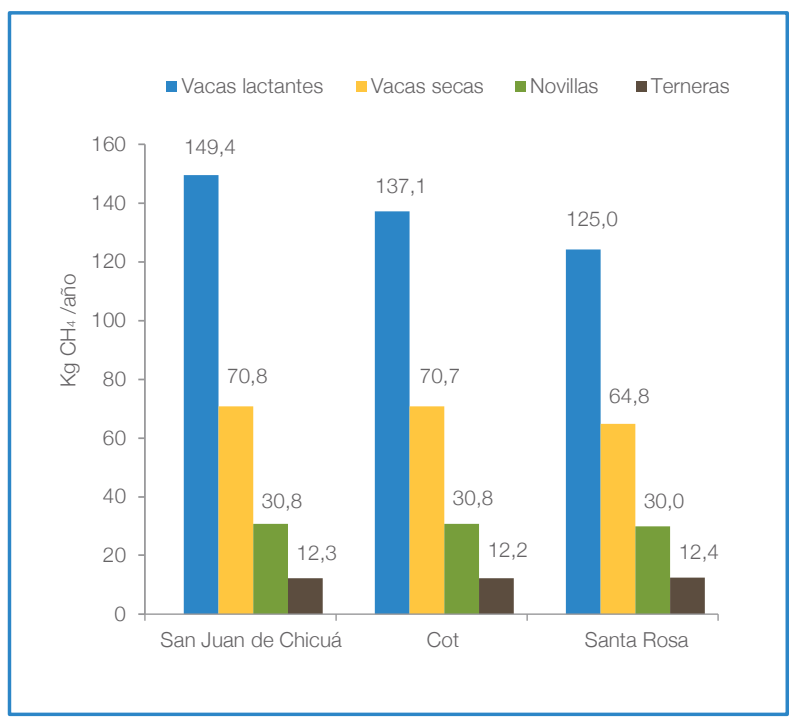

Figura 2. Emisión de metano procedente de la fermentación en el tracto digestivo, según categoría de animal, en tres fincas de lechería especializada en la zona alta de Cartago. Costa Rica. 2014.

En promedio, las vacas en producción emitieron un $50 \%$ más de metano que las secas, las cuales a su vez emitieron un 55\% y un $82 \%$ más de metano que las novillas y las terneras, respectivamente. En Santa Rosa, la emisión de metano por vaca lactante y año $(125 \mathrm{~kg})$, fue menor que en Cot $(137,1 \mathrm{~kg})$ y en San Juan de Chicuá (149,4 kg), diferencias que se mantuvieron en el caso de las vacas secas. Sin embargo, las novillas y las terneras produjeron cantidades similares en las tres fincas.

\section{Balance de gases de efecto invernadero}

Como ya se ha mencionado, en el balance se utilizó como unidad de medida el dióxido de carbono equivalente $\left(\mathrm{CO}_{2} \mathrm{eq}\right)$, para poder realizar las comparaciones entre los sistemas de producción. En el Cuadro 7 se detalla la emisión y la fijación de $\mathrm{CO}_{2}$ eq y el balance respectivo de cada sistema. 
Cuadro 7. Balance anual de dióxido de carbono equivalente $\left(\mathrm{CO}_{2} \mathrm{eq}\right)$ en toneladas/año, en tres fincas de lechería especializada en la zona alta de Cartago. Costa Rica. 2014.

\begin{tabular}{|c|c|c|c|c|}
\hline \multirow[b]{2}{*}{ Componente } & \multicolumn{3}{|c|}{ Sistema de producción } & \multirow[b]{2}{*}{ Contribución (\%) } \\
\hline & Cot & Santa Rosa & $\begin{array}{l}\text { San Juan de } \\
\text { Chicuá }\end{array}$ & \\
\hline \multicolumn{5}{|c|}{ Emisión de $\mathrm{CO}_{2}$ eq (t/ño) } \\
\hline Fermentación digestiva & 240,1 & 309,2 & 408,3 & $81,6 \pm 2,61$ \\
\hline Fertilización nitrogenada & 25,0 & 50,1 & 50,1 & $10,5 \pm 2,05$ \\
\hline Gestión del estiércol & 6,2 & 15,9 & 20,0 & $3,4 \pm 1,07$ \\
\hline Combustibles fósiles & 11,1 & 12,3 & 20,0 & $3,7 \pm 0,49$ \\
\hline Electricidad & 2,3 & 3,5 & 3,9 & $0,8 \pm 0,06$ \\
\hline Total & 284,7 & 391,0 & 502,3 & 100,0 \\
\hline \multicolumn{5}{|c|}{ Fijación de $\mathrm{CO}_{2}$ eq (t/año) } \\
\hline Bosque secundario & 0,0 & 126,9 & 22,0 & $2,2 \pm 3,20$ \\
\hline Árboles dispersos & 0,0 & 123,7 & 238,5 & $4,8 \pm 0,4,39$ \\
\hline Cercas vivas & 30,8 & 0 & 0 & $1,1 \pm 1,85$ \\
\hline Suelo & 0 & 0 & 0 & 0 \\
\hline Total & 30,8 & 250,6 & 260,5 & 100,0 \\
\hline Balance Emisión-Fijación & $+253,9$ & $+140,4$ & $+241,8$ & - \\
\hline Remoción del componente leñoso (\%) & 10,82 & 64,09 & 51,86 & - \\
\hline Corbono orgánico en el suelo (10 cm) & 931,2 & $1.898,4$ & $2.501,4$ & - \\
\hline
\end{tabular}

La fermentación en el tracto digestivo y la fertilización nitrogenada, fueron responsables de la mayor parte de las emisiones de $\mathrm{CO}_{2}$ eq $(81,6 \pm$ 2,61 y $10,5 \pm 2,05 \%$, respectivamente), mientras que la contribución de la gestión del estiércol, el uso de combustible y electricidad no superó el $4 \%$ en cada uno de los casos. Por lo que disponer de una adecuada estructuración del hato, así como optimizar la fertilización nitrogenada; es indispensable para contribuir a reducir las emisiones de GEI por kilogramo de leche producido en cada sistema de producción.

Además, en la finca de Santa Rosa, se produjo menos emisión anual de $\mathrm{CO}_{2}$ eq por hectárea $(14,06$ t), vaca $(3,26 \mathrm{t})$ y tonelada de leche producida $(0,49$ t) que en Cot y San Juan de Chicuá (Figura 3), alcanzándose en Cot las mayores emisiones por hectárea $(16,75 \mathrm{t})$ y tonelada de leche $(0,60 \mathrm{t})$ y en San Juan de Chicuá las mayores emisiones por vaca (3,86 t).

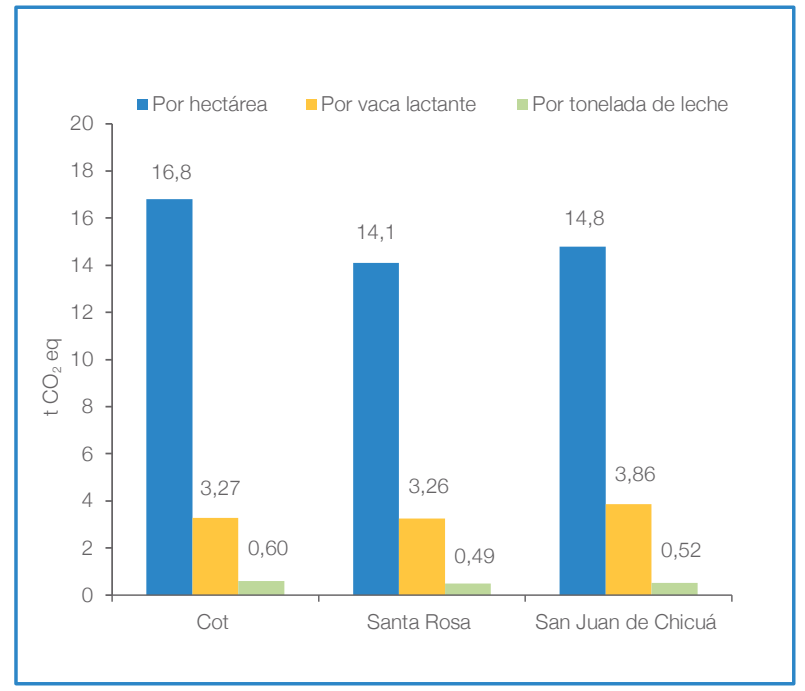

Figura 3. Emisión de dióxido de carbono equivalente $\left(\mathrm{CO}_{2}\right.$ eq) por hectárea, vaca y kilogramo de leche, en tres fincas de lechería especializada en la zona alta de Cartago. Costa Rica. 2014. 
Con respecto a la fijación de $\mathrm{CO}_{2}$ eq, la contribución del componente leñoso en el caso de Cot fue escasa, debido al único aporte de las cercas vivas, mientras que en Santa Rosa, la fijación de carbono por la biomasa fue repartida en partes iguales entre el bosque $(50,4 \%)$ y los árboles dispersos en las pasturas (49,6\%). En el caso de San Juan de Chicuá, los árboles dispersos tuvieron mayor contribución $(91,6 \%)$ que el bosque $(8,4 \%)$. En las dos últimas fincas, el componente leñoso retuvo el 64 y el $52 \%$, respectivamente, del $\mathrm{CO}_{2}$ eq emitido por los mismos sistemas, con capacidad de capturar 5,6 y 7,0 t $\mathrm{CO}_{2}$ eq ha/año, en el mismo orden. La finca de Cot, capturó en el componente leñoso únicamente el $11 \%$ del $\mathrm{CO}_{2}$ eq emitido, con fijaciones de 1,8 $\mathrm{t}$ $\mathrm{CO}_{2}$ eq ha/año.

Al realizar el balance de GEl, y tomando en cuenta únicamente las fijaciones en el componente leñoso, los valores fueron negativos en las tres fincas. Sin embaro, hay que tener presente que en el suelo de los sistemas se está reteniendo carbono, el cual no fue posible registrar debido al corto ciclo de evaluación (un año), de lo contrario, el balance probablemente se tornaría positivo, ya que en el suelo de los sistemas evaluados existe entre tres y cinco veces el carbono emitido por los mismos sistemas productivos. Otro aspecto importante a resaltar, es que del total de carbono orgánico retenido en el suelo, la mayor parte se encontró en el área de pastura de cada finca.

Las fincas de Santa Rosa y San Juan de Chicuá presentan ventaja agroecológica en comparación con la de Cot, debido a que cuentan con áreas de bosques y con seis a ocho árboles por hectárea dispersos en las pasturas, lo que fija grandes cantidad de carbono del ambiente a través del crecimiento de la biomasa, mitigando las emisiones de los GEl producidas por el mismo sistema de producción. Varios autores (Mora, 2001; Mahecha, 2002; Ibrahim et al., 2006; Ibrahim et al., 2007) indican que los árboles en pasturas no inhiben el rendimiento de MS del pasto, pero si mejoran su calidad y aportan múltiples beneficios a los animales y a los recursos naturales.

En cuanto a la estratificación del hato, los tres sistemas de producción disponen de un excesivo número de animales de reemplazo, cantidad que según Villegas (1995) no debe superar el 25\% del hato total porque restringe la eficiencia productiva y económica del sistema, y además acrecienta las emisiones de $\mathrm{CH}_{4}$. Varias investigaciones realizadas en Costa Rica (Mora, 2001; García, 2014; Iñamagua, 2014) indican que la principal fuente de GEI en los sistemas de lechería es el metano producido en el tracto digestivo de los animales, por lo que está directamente ligado al número de animales que existe en el sistema productivo. Por ello, es necesario disponer de una adecuada estratificación del hato para reducir las emisiones de GEl.

En relación con las emisiones GEl, se determinó que los tres principales gases con efecto invernadero en los sistemas de producción de leche evaluados son el dióxido de carbono $\left(\mathrm{CO}_{2}\right)$, el metano $\left(\mathrm{CH}_{4}\right)$ y el óxido nitroso $\left(\mathrm{N}_{2} \mathrm{O}\right)$. El primero fue producido, principalmente, por el uso de combustibles fósiles (69\%), el segundo como consecuencia esencial de la fermentación en el tracto digestivo de los animales (97\%) y el último, a causa de la fertilización nitrogenada de las pasturas y forrajes (88\%). Estos resultados concuerdan con los obtenidos por Mora (2001), García (2014) e lñamagua (2014) en estudios realizados en sistemas de lechería en Costa Rica.

Las emisiones de metano por vaca lactante oscilaron entre 125 y 149 kg/año, obteniendo la finca de Santa Rosa las menores producciones anuales por hectárea $(0,529$ t), por vaca en producción $(125 \mathrm{~kg})$ y por kilogramo de leche producido $(18,46 \mathrm{~g})$. Estos resultados se deben a que en esta finca los animales son de menor tamaño (Jersey), por lo que pesan y consumen menos MS que las Holstein, lo que repercute en una menor emisión de metano por animal. Estos argumentos concuerdan con los brindados por León et al. (2012) y Guzman y Sager (2013), que afirman que los bovinos con bajo peso corporal demandan menos consumo de MS y energía que los de mayor peso, por lo que emiten menos $\mathrm{CH}_{4}$. Mora (2001) también reporta una mayor emisión de metano por vaca (470 g/día) a mayor peso (450 kg PV) y consumo de MS (13,8 kg MS/ día), en comparación con vacas de peso entre 350 y $400 \mathrm{~kg}$ PV y consumos de 10,8 a 11,2 kg MS/día, respectivamente (388 y $463 \mathrm{~g} \mathrm{CH}_{4} / \mathrm{vaca} /$ día, en el mismo orden).

Los valores de emisión de metano obtenidos por vaca, fueron inferiores a los que reportan Mora (2001) en Cartago (161 kg/año) con vacas lactantes en pastoreo rotacional, mientras que Iñamagua (2014) encontró emisiones inferiores (97,8 
\pm 49,71 kg/año) en una muestra de 104 fincas en Costa Rica. También los valores encontrados por Montenegro y Abarca (2001) y por el IMN (2014) son inferiores (90,9 y 85,0 kg vaca/año) a los obtenidos en este estudio. Esta discrepancia demuestra que la emisión de metano por parte de los bovinos de leche en Costa Rica es muy variable, debido a que está sujeta a variables de manejo y ambientales, tales como: raza, peso, estado fenológico, manejo, producción de leche y alimentación de los los animales; las cuales son muy heterogéneas en los sistemas ganaderos dedicados a la producción de leche existentes en nuestro país.

La emisión total de metano por kilogramo de leche producido varió entre explotaciones, con valores que oscilaron entre 18,46 y 24,05 g, alcanzando las fincas de Santa Rosa y Cot las menores y mayores emisiones, respectivamente, mientras que en San Juan de Chicuá la emisión fue intermedia (20,29 g). Estas diferencias pueden ser explicadas por el hecho de que en Santa Rosa se produce un mayor rendimiento diario de leche por vaca $(23 \mathrm{~kg})$ que en Cot $(21 \mathrm{~kg})$ y una menor emisión de $\mathrm{CH}_{4}$ por vaca $(125,137,1$ y 149,4 kg/año para Santa Rosa, Cot y San Juan de Chicuá, respectivamente). Las diferencias entre Cot y San Juan de Chicuá se explican porque en la segunda finca la producción diaria por vaca es mayor $(25 \mathrm{~kg}$ ) que en la primera. Los valores obtenidos no estuvieron muy lejos del rango (19 a $22 \mathrm{~g} \mathrm{CH}_{4}$ por $\mathrm{kg}$ de leche) reportado por Montenegro y Abarca (2001) al evaluar vacas lactantes pastando estrella y kikuyo en la zona alta de Costa Rica. Sin embargo, Mora (2001) reporta emisiones ligeramente superiores, entre 23,5 y 27,2 $\mathrm{g}$ por kg de leche, en vacas pastoreando kikuyo.

Al convertir los tres principales $\mathrm{GEI}\left(\mathrm{CO}_{2}, \mathrm{CH}_{4}\right.$ y $\mathrm{N}_{2} \mathrm{O}$ ) a dióxido de carbono equivalente $\left(\mathrm{CO}_{2} \mathrm{eq}\right)$, se determinó que en términos medios, la fermentación en el tracto digestivo y la fertilización nitrogenada fueron responsables de los mayores aportes $(81,6$ $\pm 2,61$ y $10,5 \pm 2,05 \%$, respectivamente), mientras que la gestión del estiércol, el uso de combustible fósiles y la electricidad no superaron el 3,5, 3,7 y $1 \%$, respectivamente. Al respecto, García (2014) analizó la correlación de 14 variables de manejo con la producción de $\mathrm{CO}_{2}$ eq, encontrando que el número de vacas lactantes, secas y novillas, fue la variable que presentó mayor correlación positiva con la emisión de $\mathrm{CO}_{2}$ eq, mientras que el uso de combustibles fósiles y de electricidad fueron las variables con menor correlación. Velthof et al. (1996) también encontraron una correlación positiva entre la fertilización nitrogenada de las pasturas y la emisión de GEl en fincas de lechería.

Las emisiones anuales de $\mathrm{CO}_{2}$ eq por hectárea $(14,06$ t) y vaca $(4,12$ t) encontradas por García (2014) fueron inferiores a las alcanzadas en Cot $(16,75$ y $4,59 \mathrm{t}$, respectivamente) y San Juan de Chicuá ( 14,77 y 4,78 t, en el mismo orden). Otro aspecto importante es que en la finca de Santa Rosa se logró una mejor relación de t $\mathrm{CO}_{2}$ eq: tonelada de leche producida $(0,49: 1)$, en comparación con Cot $(0,60: 1)$ y San Juan de Chicuá $(0,52: 1)$. Por tanto, parece evidente que las menores emisiones de GEI de la finca de Santa Rosa obedecen al tipo de animal del que disponen, ya que, como se ha indicado, las vacas Jersey consumen menos MS que las Holstein, por lo que emiten menos $\mathrm{CH}_{4}$ y $\mathrm{CO}_{2}$ eq.

Con respecto a la fijación de carbono, se determinó que en las tres fincas el $\mathrm{CO}_{2}$ eq contenido en el suelo a los $10 \mathrm{~cm}$ de profundidad superó entre 3,3 y 5,0 veces al $\mathrm{CO}_{2}$ eq emitido por los sistemas productivos. Sin embargo, en el presente trabajo, debido al corto periodo de evaluación (un año) no fue posible demostrar que gran parte de este carbono es retenido por los mismos sistemas por año, lo que significa que si se pretende determinar la cantidad de carbono retenido en los sistemas ganaderos de la zona alta de nuestro país, probablemente es necesario realizar evaluaciones durante varios años, con mediciones tanto en la época seca como en la lluviosa.

El promedio de $\mathrm{CO}_{2}$ eq retenido en el suelo fue de $54,9 \pm 12,65 \mathrm{t} / \mathrm{ha}$, valor ligeramente inferior al rango de 55 y 57,1 t/ha encontrado por García (2014) a la misma profundidad en seis fincas estudiadas en la zona alta de Costa Rica. Sin embargo, (Ibrahim et al. 2007) reportan que en pasturas degradas el acúmulo es menor (21,7 t/ha) y mayor cuando el muestreo se realiza entre 0 y $100 \mathrm{~cm}$ de profundidad (119,2 t/ha). Una situación semejante ha sido descrita por Mora (2001) al muestrear entre 20 y $60 \mathrm{~cm}$ de profundidad (132,2 y 153,4 t/ ha, respectivamente). Sin embargo, ninguno de estos autores encontró diferencias de acúmulos de carbono en suelos con pasturas sin o con árboles dispersos. 
El componente leñoso también cumplió un papel importante como sumidero de carbono en los sistemas de producción, principalmente en las fincas de Santa Rosa y San Juan de Chicuá, donde dicho componente fijó el 63,8 y el 51,9\% del $\mathrm{CO}_{2}$ eq emitido por los sistemas, respectivamente, mediante el crecimiento de la biomasa del bosque segundario y los árboles dispersos en las pasturas. En estas dos explotaciones se dispuso de una densidad de 8 y 6 árboles por hectárea, según el mismo orden de las fincas. Por el contrario, en la finca de Cot no existe bosque ni árboles dispersos en las pasturas, solamente cercas vivas, las cuales fijaron únicamente el 10,8 \% del $\mathrm{CO}_{2}$ eq emitido por el sistema. Esta situación resalta la importancia de los bosques, los árboles dispersos en las pasturas y las cercas vivas en el equilibrio ambiental de los sistemas ganaderos.

En un estudio realizado por García (2014) sobre el balance de GEl en seis fincas en el trópico húmedo de Costa Rica, con cargas que oscilaron entre 1,1 y 1,7 unidades animal/ha y densidades de 2 a 7 árboles/1000 $\mathrm{m}^{2}$ dispersos en las pasturas, áreas de bosque y cercas vivas, se encontraron fijaciones de carbono entre 61 y $166 \%$ del $\mathrm{CO}_{2}$ eq emitido por los sistemas. En este mismo estudio también se determinó que, de 14 variables analizadas, el diámetro del árbol, la altura y la cantidad de árboles, fueron las variables que presentaron mayor correlación positiva con la fijación de $\mathrm{CO}_{2}$ eq en los sistemas de producción.

La fertilización nitrogenada es indispensable para optimizar el rendimiento de las pasturas y los forrajes. Sin embargo, el uso excesivo incrementa las emisiones de óxido nitroso y por ende de los gases de efecto invernadero. Por lo tanto, a pesar de que el metano de origen digestivo es el GEl más relevante en los sistemas ganaderos, realizar esfuerzos por reducir emisiones provenientes de fertilización nitrogenada podría tener resultados a corto plazo si se realiza en fincas con exceso de uso del fertilizante.

El componente leñoso y el suelo son sumideros importantes de carbono orgánico. El primero, mediante una adecuada distribución del bosque, árboles dispersos en las pasturas y cercas vivas, podría capturar más del 50 \% del dióxido de carbono equivalente emitido por el sistema, situación que permite un acercamiento al equilibrio ambiental de las lecherías. En el caso del suelo, se requiere realizar evaluaciones a mediano y largo plazo, en diferentes tipos de suelo y épocas del año, así como en condiciones diferentes de manejo de las pasturas, con el fin de cuantificar con mayor exactitud el aporte al sistema.

Las emisiones de gases de efecto invernadero en los sistemas ganaderos, es un fenómeno dinámico y complejo, donde intervienen e interactúan una serie de factores y componentes internos y externos al sistema. Si bien es importante y de interés nacional e internacional la reducción de las emisiones de los GEl por parte del sector, lo es también la evaluación de la sostenibilidad de los sistemas ganaderos ante la dependencia de fuentes de alimentación externas, los fenómenos globales y el cambio climático.

El gas metano producido por la fermentación entérica de los animales, la fertilización nitrogenada de las pasturas y la gestión del estiércol son responsables del $95 \%$ del total de $\mathrm{CO}_{2}$ eq emitido por los sistemas de producción de leche, mientras que la contribución del uso de combustibles fósiles y de electricidad no supera el $5 \%$. En consecuencia, una adecuada estructuración del rebaño y apropiada fertilización nitrogenada, son factores esenciales para reducir las emisiones de gases de efecto invernadero por kilogramo de leche producida. 


\section{LITERATURA CITADA}

Abarca, S. 2013. Cambio climático y la mitigación en fincas lecheras. Revista Universidad Técnica Nacional (63):28-31.

Association of Official Analytical Chemist (AOAC). 1970. Methods of analysis of the official chemist. 2 ed. Washington, DC, Estados Unidos de América. $1015 \mathrm{p}$.

Bolaños, R; Watson, V. 1993. Mapa ecológico de Costa Rica, según el sistema de clasificación de zonas de vida del mundo de L.R. Holdridge. San José, Costa Rica. Centro Científico Tropical. ICE. Escala 1:200.000.

Botero, R. 2013. El cambio climático y su mitigación en los sistemas agropecuarios tropicales (en línea). Engormex. Consultado 28 set. 2015. Disponible en http://www.engormix.com/MA-ganaderia-leche/ manejo/articulos/cambio-climatico-mitigacion-sistemas-t5069/124-p 0.htm.

Cabrera, V; Sols, D; del Corral, J. 2010. Determinants of Technical Efficiency among Dairy Farms in Wisconsin. Journal of Dairy Science (93):387-393.

De Melo y Abarca, 2008. Cafetales para servicios ecosistémicos, con énfasis en el potencial de sumideros de carbono. Informe Final. Turrialba, Costa Rica. 61 p.

Forsythe, W. 1972. Manual de Laboratorio de Física del suelo. Turrialba, Costa Rica. IICA. 216 p.

Friedrich-Wilhelm, G; Werner, P. 2008. Climate development in the last Century-Global regional. International Journal of Medical Microbiology 298(1):5-11.

García, K. 2014. Propuesta de alternativas de reducción de gases de efecto invernadero (GEI) para los sistemas lecheros de San Joaquín de Tuis de Turrialba. Tesis Mag. Sc. Heredia, Costa Rica. Universidad Nacional de Heredia. 78 pp.

González, BF; Rodríguez, H. 1999. Proyección de las emisiones de gases de efecto invernadero (GEI), Colombia 1998-2010. Revista Académica Colombiana de Ciencias 23(89):497-505.

Guzman, ML; Sager, SL. 2013 Inventario de metano entérico de los sistemas de producción de carne para San Luis en el año 2009. RIA 39(1):88-94.
Ibrahim, M; Mora, J; Rosales, M. 2006. Potencialidades de los sistemas silvopastoriles para la generación de servicios ambientales. Informe de Memoria. Centro Agronómico Tropical de Investigación y Enseñanza (CATIE). Turrialba, Costa Rica. 199 p.

Ibrahim, M; Chacón, M; Cuartas, C; Naranjo, J; Ponce, G; Vega, P; Casasola, F; Rojas, J. 2007. Almacenamiento de carbono en el suelo y la biomasa arbórea en sistemas de usos de la tierra en paisajes ganaderos de Colombia, Costa Rica y Nicaragua. Agroforestería en las Américas (45):27-36.

Instituto Meteorológico Nacional (IMN). 2014. Inventario nacional de gases de efecto invernadero y absorción de carbono 2010 (en línea). San José, Costa Rica. 64p. Consultado 25 jun. 2015. Disponible en http://cglobal.imn.ac.cr/documentos/ factores-de-emision-gei-quinta-edicion.

Instituto Meteorológico Nacional (IMN). 2015. Factores de emisión de gases efecto invernadero (en línea). 5 ed. San José, Costa Rica. 9 p. Consultado 25 jun. 2015. Disponible en http://cglobal.imn. ac.cr/sites/default/files/documentos/factoresemision-gei-2015.pdf.

Instituto Meteorológico Nacional (IMN). 2008. El clima, variabilidad y cambio climático en Costa Rica. San José, Costa Rica. Comité Regional de Recursos Hídricos. p. 20-23.

Intergovernmental Panel on Climate Change (IPCC). 2006. Guidelines for National Greenhouse Gas Inventories. In Dong $\mathrm{H}$; Mangino J; McAllister TA; Hatfield JL; Johnson DE; Lassey KR; de Lima M; Romanovskaya A (eds.). Chapter 10. Emissions from livestock and manure management. Kanagawa, Japan, Institute for Global Environmental Strategies (IGES). $87 \mathrm{p}$.

Iñamagua, JP. 2014. Estrategias de alimentación, emisiones de gases efecto invernadero y relación ingresos-costos de alimentación asociados a la producción de leche en fincas productoras de leche de la Cooperativa Dos Pinos, en Costa Rica. Tesis Mag. Sc. Turrialba, Costa Rica. Centro Agronómico Tropical de Investigación y Enseñanza (CATIE). 77 p. 
Lascano, CE; Cárdenas, E. 2010. Alternatives for methane emissions mitigation in livestock systems. Revista Brasilera de Zootecnia 39:175-182.

León, JA; Zamora, HD; León, JA. 2012. Estrategias de mitigación ante el cambio climático en fincas ganaderas altoandinas del departamento de nariño. Revista Unimar 59(1):23-38.

Mahecha, L. 2002. El silvopastoreo: una alternativa de producción que disminuye el impacto ambiental de la ganadería bovina. Revista Colombiana de Ciencias Pecuarias, 15(2):226-231.

Montenegro J; Abarca, S. 2001. Importancia del sector agropecuario costarricense en la mitigación del calentamiento global. San José, Costa Rica. Ministerio de Agricultura y Ganadería (MAG), Instituto Meteorológico Nacional (IMN). 96 p.

Mora, V. 2001. Fijación, emisión y balance de gases de efecto invernadero en pasturas en monocultivo y sistemas silvopastoriles en fincas lecheras intensivas en la zona alta de Costa Rica. Tesis Mag. Sc. Turrialba, Costa Rica. Centro Agronómico Tropical de Investigación y Enseñanza (CATIE). 92 p.

Moss, A. 2000. Methane production by ruminants: its contribution to global warming. Annales de Zootechnie Journal 49(3):231-253.

Niggli, U; Fliebbach, A; Hepperly, P; Scialabba, N. 2009. Low Greenhouse gas Agriculture: Mitigation and adaptation potential of sustainable farming systems. FAO, Roma, Italia. Paginación.

Russo, R. 2009. Guía práctica para la medición de la captura de carbono en la biomasa forestal. Limón, Costa Rica. Universidad EARTH. 17 p.
Shallcross, DE; Khalil, MAK; Butenhoff, CL. 2007. The atmospheric methane sink. In Reay, DS; Hewitt, CN; Smith, KA; Grace, J (eds.). Greenhouse Gas Sink. Wallingford, UK. CAB International. p. 171-183.

Solano, J; Villalobos, R. 2001. Aspectos fisiográficos aplicados a un bosquejo de regionalización geográfica-climática de Costa Rica. Tópicos Meteorológicos y Oceanográficos 8(1):26-39.

Tabatabai, MA; Bremner, JM. 1970. Use of the Leco Automatic 70-Second Carbon Analyzer for Total Carbon Analysis of Soils. Soil Science Society of America Journal 34(4):608-610.

Veldkamp, E. 1993. Soil organic carbon dynamics in pastures established after deforestation in the humid tropics of Costa Rica. Tesis Ph. D. Wageningen, Netherlands. Wageningen University \& Research. $117 \mathrm{p}$.

Velthof, G; Jarvis, S; Stein, A; Allen, A; Oenema, O. 1996. Spatial variability of nitrous oxide fluxes in mown and grazed grassland on a poorly drained clay soil. Soil Biology and Biochemistry 28(9):1215-1225.

Villegas, LA. 1995. Actividad lechera. In Atlas Agropecuario de Costa Rica. UNED. San José, Costa Rica. p. 459-465

Walkey, A; Black, Al. 1934. An examination of the Degtjoreff method for determination soil organic matter, and a proposed codification of the cromic acid titration method. Soil Science 37:29-38. 


\section{INFORMACIÓN PARA LOS AUTORES}

La publicación de la revista Alcances Tecnológicos, se inició durante el año 2003 y es una de las actividades relevantes del área de transferencia de tecnología del INTA, la revista tiene carácter técnico-científico y se publica un número cada dos años. Se reciben los artículos que cumplan con los requisitos, que sean originales y que no han sido publicados en otra revista.

\section{TIPOS DE DOCUMENTOS RECIBIDOS}

\section{Artículos científicos}

Se refiere a una investigación detallada con resumen, introducción, materiales y métodos, resultados y discusión y literatura citada. Se debe demostrar la profundidad del estudio y resaltar los méritos del trabajo para su publicación como artículo científico. La extensión máxima es de 30 páginas en Microsoft Word a espacio sencillo y con tipografía Arial 12.

\section{Notas técnicas}

Se refiere a una publicación con la misma estructura de un artículo científico, sin su nivel de detalle. La extensión máxima es de 30 páginas.

\section{Revisiones bibliográficas}

Son recopilaciones y síntesis del conocimiento existente en un campo específico de interés en las ciencias agrícolas. Se debe incluir resumen, introducción y el contenido. Extensión máxima 30 páginas y con un mínimo de 25 referencias bibliográficas.

\section{Análisis y comentario}

Es el análisis de una situación específica, realizado por un especialista con reconocida trayectoria en el campo. Se debe incluir resumen, introducción, el contenido y la literatura citada. Extensión máxima 10 páginas.

\section{Informaciones técnicas}

Están enfocadas en aprovechar la amplia experiencia de un especialista en un campo específico. Se debe incluir resumen, introducción, el contenido y la literatura citada. Extensión máxima 15 páginas.

\section{Comunicaciones cortas}

Son resultados preliminares de interés para el sector agropecuario. Debe contener introducción, resultados y la literatura citada. Extensión máxima 10 páginas. 